Çukurova Üniversitesi Mühendislik Mimarlık Fakültesi Dergisi, 29(1), 99-108 ss., Haziran 2014

Çukurova University Journal of the Faculty of Engineering and Architecture, 29(1), pp. 99-108, June 2014

\title{
Haşil Prosesinin Teknik İncelemesi ve Bir Uygulama
}

\author{
Emel Ceyhun SABIR ${ }^{1 *}$, Çiğdem SARPKAYA ${ }^{2}$ \\ ${ }^{1}$ Ç. Ü., Mühendislik-Mimarlık Fakültesi, Tekstil Mühendisliği Bölümü, Adana \\ ${ }^{2}$ Harran Üniversitesi, Akçakale M.Y.O., Tekstil Teknolojisi Programı, Şanlıurfa
}

\begin{abstract}
Özet
Bu çalıșmada, dokuma ișletmelerinde iplik kopușlarını azaltmak amacıyla uygulanan bir ön ișlem olan haşıl prosesi teknik olarak incelenmiştir. Öncelikle teknik incelemede proseste kullanılan materyaller, proses değerleri, iş etüdü, maliyet gibi veriler elde edilmiş̧ir. Teknik inceleme sonucunda haşıllı ipliğin kalite parametreleri ve bu parametreler üzerinde etkili olan haşıl proses parametreleri belirlenmiştir. Bu parametreler seçilen bir iplik türü için uygulamanın işletme koşullarında yapıldı̆̆ı bir deneysel çalışmayla incelenmiştir. Seçilen iplik Ne 28/1 ve \%20 Polyester -\%80 Viskon (Pes / Vis 20/80) harmanından mamuldür. Bu iplikler 28,30 ve $40 \mathrm{Ns} / \mathrm{m}^{2}$ viskozitede, 50 ve $70 \mathrm{~m} / \mathrm{dk}$ makine çalışma hızlarında haşıllanarak haşıl alma oranı, iplik rutubeti, çözgü mukavemeti ve dokuma makinesi randımanı ölçülmüştür.
\end{abstract}

Anahtar Kelime: Haşıllama işlemi, Haşıl proses parametreleri, İş etüdü

\section{The Technical Review for the Sizing Process and an Application}

\begin{abstract}
In this study, the sizing process being pre-processing which is applied in order to reduce yarn breakage in weaving mills, has been technically examined. First of all, in the technical review, the materials used in the process, process values, work-study, cost data were obtained. As a result of technical analysis, sized yarn quality parameters, sizing process parameters being effective on these parameters were determined. These parameters were examined for selected yarn in the mill conditions with experimental study. The selected yarn is Ne 28/1 and 20\% Poliester - 80\% Viscose (Pes / Vis 20/80) blend. The yarns were sized in viscosity 28,30 and $40 \mathrm{Ns} / \mathrm{m}^{2}$ and sizing machine speed between 50 and $70 \mathrm{~m} / \mathrm{min}$, and then, sizing ratio, yarn moisture, warp strenght and weaving machine efficiency were measured.
\end{abstract}

Key Words: Sizing process, Sizing process parameters, Work study

\footnotetext{
* Yazışmaların yapılacağı yazar: Emel Ceyhun SABIR, Ç.Ü. Mühendislik Mimarlık Fakültesi, Tekstil Mühendisliği Bölümü, Adana.emelc@cu.edu.tr
} 


\section{GíRiş}

Haşıllama işleminin amacı ipliklere dokunabilirlik özelliği kazandırmak gibi görünse de, dokumada randıman ve kaliteyi arttırmak, düzgün bir kumaş yüzeyi elde etmek, terbiye işlemleri sırasında kolaylıkla ve liflere zarar vermeden sökülebilmesi, ham ve mamul kumaş maliyetlerini arttırıcı olmaması gibi amaçlar da haşıllama işleminin amaçlarındandır .

Haşıl prosesinde düşük maliyette kalitenin ve verimliliğin geliştirilmesi için yapılan çalışmalar optimum haşıllama koşullarının belirlenmesi, kurutma enerjisinin azaltılması için alternatif kurutma tekniklerinin araştırılması, çözgü kopuş tahmini için yapılan çalışmalar ve haşıl maddesinin geri kazanımı vb. gibi şeklindedir. Hari ve Tewary yapmış oldukları çalışmada, yüksek nem oranlarının iplik kalitesi özelliklerini arttırıp arttırmadığ1 ya da dokuma aşamasında haşıllanmış ipliklerin dokunabilirliğinde oluşan zararları azaltıp azaltmadığını belirlemeye çalışmışlardır [1]. Eken, dokuma makinesinin randımanını artırmak ve kumaş kalitesini yükseltmek için yapılan haşıllama işleminin çözgü iplik özellikleri üzerine yaptığ 1 etkileri belirlemiştir [2]. Trauter ve Stegmaier 1992 yılında yaptıkları çalışmada haşıllama derecesi ayarlanması konusunda Institut für Textil und Verfahrenstechnik (ITV) tarafindan 1982 'de teklif edilen sistemin düzeltilmiş ve geliştirilmiş biçimini sunmuşlardır [3]. Kovacevic ve ark. yapmış oldukları çalışmada, dokuma makinesindeki her bölümden alınan çözgü ipliğinin kırılma gücü, farklı dokuma makinelerinde aynı çözgüden alınan 3 farklı dokuma kullanılarak ölçmüşlerdir. Çözgü ipliklerinin deformasyonunu simule etmek için çözgü leventlerinden örnekler almışlar ve çözgü deformasyonunda en uygun dokuma tipi ve makindeki her kesimde oluşan dokuma prosesi tespit edilmiştir [4]. Sabır ve Sarpkaya, tekstil işletmeleri için önemli olan ve dokuma randımanını etkileyen haşıl prosesinin geleneksel uygulamaları, haşı prosesi maliyeti ve haşıllama işlemi sırasında karşılaşılan sorunları incelemişlerdir. $\quad 1000 \mathrm{~m}$ çözgü haşıllama maliyetinin 214 TL olarak tespit etmişlerdir [5]. Djordjevic ve diğerleri, pamuklu çözgü ipliklerinin haşıllama prosesinde kullanılan akrilik asid ve kopolimer akril amid solüsyonunun reolojisi hakkında bir çalışma yapmışlardır [6].

Bütün bu çalışmalar haşıl prosesinin önemini açıkça ortaya koymaktadır. Haşıllama Prosesi, dokuma prosesi öncesi yürütülen ve dokuma işleminin performansını doğrudan etkileyen, işletmede kapladığı fiziki alan (yaklaşık $60 \mathrm{~m}$ ), tükettiği enerji (buhar eldesinde harcanan enerji doğal gaz enerjisi olup ayda 150.000 standart $\mathrm{m}^{3}$ 'tür.Haşıl makinesinin çekmiş olduğu elektrik enerjisi ise saatte $32 \mathrm{~kW}$ 'dir), çevreye verdiği atık miktarı (kullanılmış haşıl çözeltisinde mevcut bulunan haşıl maddeleri, atık su) ve proseste uzmanlık gerektiren yönüyle incelenmesi gereken önemli bir prosestir.

$\mathrm{Bu}$ çalışmada, haşıl prosesine göre iplik türleri, işletme haşıl prosesi verileri, haşıl maddeleri ve haşıl prosesi iş etüdü anlatılmış ve haşıl prosesine etki eden parametreler belirlenmiştir. Ne 28/1 $\mathrm{Pes} / \mathrm{Vis}$ 20/80 harman iplik seçilerek bu iplikler 28,30 ve $40 \mathrm{Ns} / \mathrm{m}^{2}$ viskozite, 50 ve $70 \mathrm{~m} / \mathrm{dk}$ hızlarda haşıllanarak haşıl alma oranı, iplik rutubeti, çözgü mukavemeti ve dokuma makinesi randımanı ölçülerek ölçüm sonuçları değerlendirilmiştir.

\subsection{Haşıl Prosesine Göre İplik Türleri ve Proses Verileri}

Selülozik kısa liflerden yapılmış ince ipliklerin mukavemetlerinin düşük olmasından ötürü bu tür ipliklere haşıllama yapılır. Haşıllama işlemi ince flamentli bükümsüz sentetik ipliklere de uygulanmaktadır. Katlı selülozik liflerden yapılmış ipliklere kumaşta renk, kalite ve parlaklık önemli ise haşıllama yapılır [7]. Haşıllama işlemleri aşağıda tablo şeklinde verilen iplik materyallerine yaygın olarak verimli şekilde uygulanmaktadır.

Kullanılan iş akış ayarları çizelge 2'de toplu halde özetlenmiştir. Çizelge 2'deki parametreler 7 farklı gruba ayrılmış olup çizelgenin 1. sütununda belirtilmiştir. 12 adet numune iplik ise Open-End, Ring, Keten Karışımı ve Pes/Vis Karışımı şeklinde 
Çizelge 1. Seçilmiş 12 farklı numunenin haşıl prosesinden geçişi için işletmelerde çalışılabilecek iplik özellikleri

\begin{tabular}{|c|c|c|}
\hline İPLİK GRUBU & $\begin{array}{l}\text { İPLİK } \\
\text { KODU }\end{array}$ & $\begin{array}{c}\text { İPLİK } \\
\text { NUMARASI } \\
\text { (Ne) }\end{array}$ \\
\hline \multirow{2}{*}{ OPEN-END } & 1 & 12/1 PAMUK \\
\hline & 2 & 20/1 PAMUK \\
\hline RİNG & 3 & 80/2 PAMUK \\
\hline \multirow{3}{*}{$\begin{array}{l}\text { KETEN } \\
\text { KARIŞIMI }\end{array}$} & 4 & $\begin{array}{l}12 / 1 \\
\text { VIS/KETEN } \\
(4000 \text { tel })\end{array}$ \\
\hline & 5 & $\begin{array}{l}12 / 1 \\
\text { VIS/KETEN } \\
(4092 \text { tel })\end{array}$ \\
\hline & 6 & $\begin{array}{l}16 / 1 \\
\text { KARDE/KETEN }\end{array}$ \\
\hline \multirow{6}{*}{$\begin{array}{l}\text { PES/VIS } \\
\text { KARIŞIMI }\end{array}$} & 7 & 40/2 PES/VIS \\
\hline & 8 & 44/2 PES/VİS \\
\hline & 9 & 50/2 PES/VİS \\
\hline & 10 & $\begin{array}{l}28 / 1 \\
\text { PES/VİS( } 8640 \\
\text { tel) }\end{array}$ \\
\hline & 11 & $\begin{array}{l}\text { 28/1 PES/VİS } \\
\text { (5112 tel) }\end{array}$ \\
\hline & 12 & 36/1 PES/VİS \\
\hline
\end{tabular}

gruplandırılmıştır. Bu verilerle haşıllanan ipliklerle yüksek randımanlı dokuma gerçekleştirilebilmektedir. Bu çizelgedeki teknik veriler Şekil 1'de resmi görülen Benninger marka 2009 model makineye aittir.

Haşıl Maddeleri : Günümüzde işletmelerde haşıl çözeltilerinde doğal ve sentetik kaynaklı haşıl maddeleri kullanılmaktadır. Nişasta ve türevleri doğal kaynaklı haşıl maddelerini, polivinilalkoller ve poliakrilatlar ise sentetik kaynaklı haşıl maddelerini oluştururlar [8].

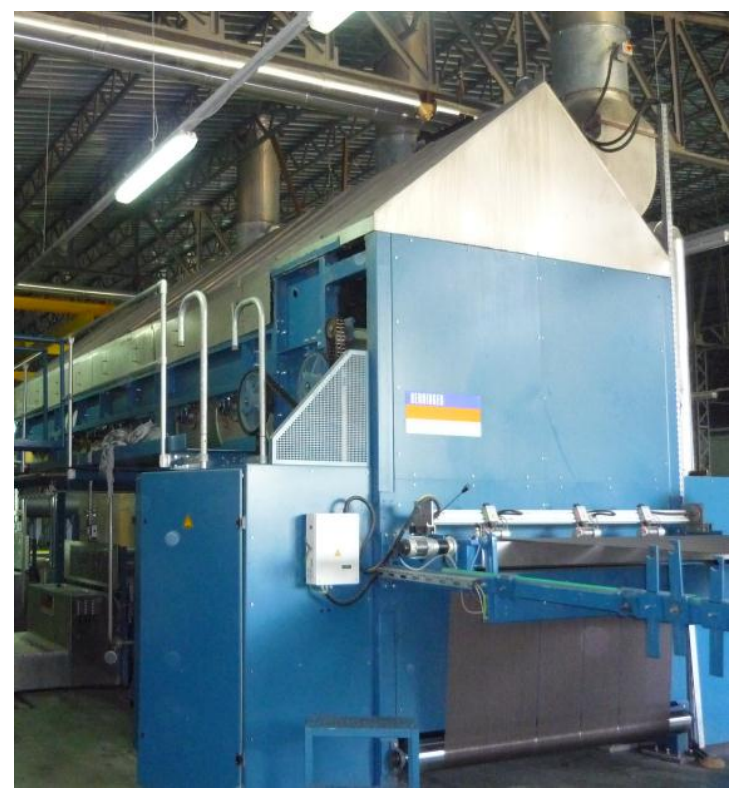

Şekil 1. Benninger marka haşıl makinesi

\subsection{Haşıl Prosesi İş Akışı}

Şekil 2'de haşıl prosesinin iş akış diyagramı verilmiştir. İş akışında temel adımlar çözgü hazırlama, haşıllama ișlemi, haşıllı ipliğin kurutulması, haşıllanan ipliğin dokuma levendine sarımı şeklindedir. Şekil 3'de geleneksel haş1 makinesi iş akışı görülmektedir. Haşıl makinesi temel olarak; besleme kısmı (1), haşıl teknesi (2), kurutma bölgesi(3) ve dokuma levendine sarım bölümlerinden(4) oluşmaktadır. Şekilde kurutma bölgesindeki bölümde (3) atık olarak verilen is1 işletme koşulları açısından büyük önem taşımaktadır. (Bu akışa sahip makine resmi Şekil 1'de verilmiştir.)

\subsection{Haşıl İş Etüdü}

Haşıllama işlemi için yapılan iş etüdü de Çizelge 3'de verilmiştir. İş etüdü 1000 m'lik çözgü ipliği için işletme şartlarında gözlem sonucu yapılmıştır. $\mathrm{Bu}$ proseste $1000 \mathrm{~m}$ çözgü ipliği için yapılan işler yaklaşık $252 \mathrm{dk}$ sürmektedir. Bu etütte bu işler için iki personel istihdam edildiği tespit edilmiştir. Çizelgeden de anlaşıldığı üzere 1000 m'lik çözgü ipliğinin haşıllanma süresi yaklaşık 4,5 saat sürmektedir. 
Çizelge 2. İşletme haşıl prosesi verileri

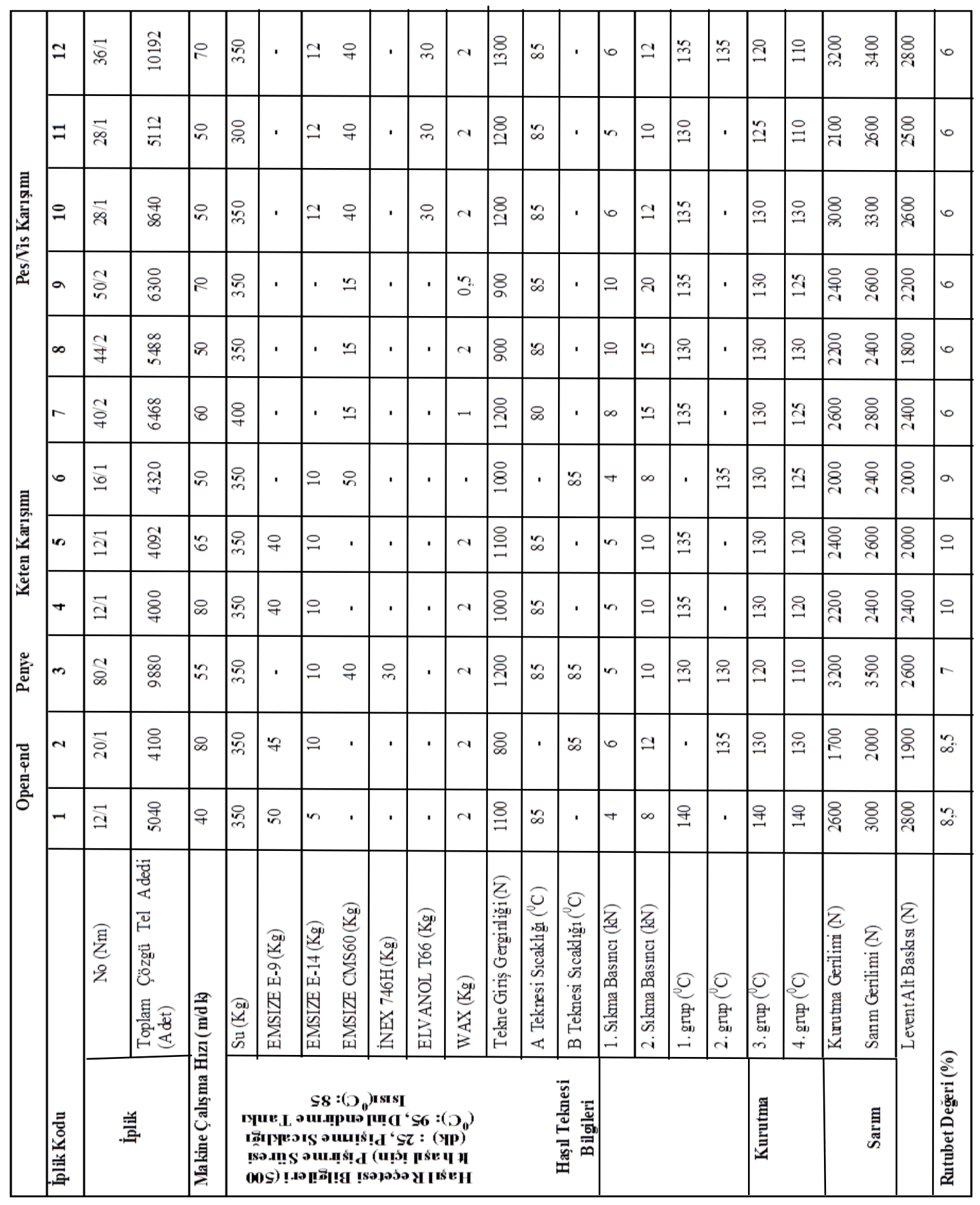




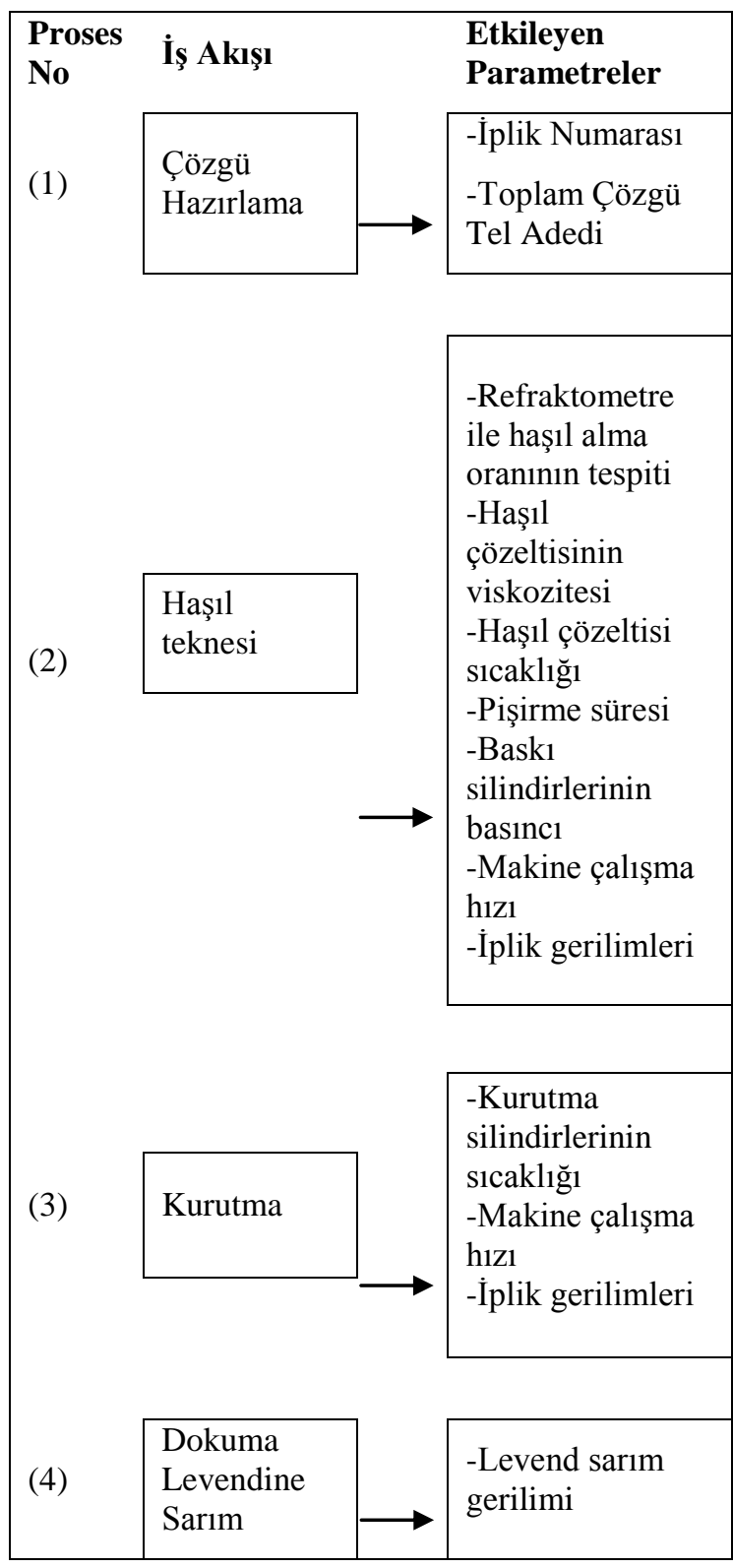

Şekil 2. Haşıl prosesi iş akış şeması

\subsection{Haşıl Prosesine Etki Eden Parametreler}

Seçilmiş işletmelerde yapılan etütler; haşıllama işlemi sonunda belirlenmesi gereken en önemli çıktıların çözgü ipliği mukavemeti, rutubet, haşıl alma oranı ve dokuma makinesi randımanı olduğunu göstermiştir.

$\mathrm{Bu}$ nedenle bu parametreleri etkileyen diğer parametreler tespit edilmiş ve Şekil 4 ve Şekil 5 de neden-sonuç diyagramlarıyla gösterilmiştir. Çözgü mukavemeti, rutubet, haşı alma oranı, dokuma makinesi randımanı kalite özelliklerine etki eden parametreler belirli bir etüt süresince incelenmiş ve etkenler içinde en etkili olanlar tespit edilmiştir (kümülatif toplamda en az \%70).

\section{SEÇILIMIŞ BİR İŞLETMEDE UYGULAMA}

\subsection{Materyal}

Çizelge 1'deki veriler ışı̆̆ında çalışmada $\mathrm{Ne}$ 28/1\%20 Poliester- \%80 Viskon (Pes/Vis 20/80 Harman) iplik üzerinde haşıl alma oranını, iplik rutubetini, iplik mukavemetini ve dokuma makinesi randımanını doğrudan etkileyebilecek makine çalışma hızı ve haşıl çözeltisi viskozitesi üzerinde denemeler yapılmıştır.

\subsection{Metod}

Seçilen iplik materyali ( $\mathrm{Ne}$ 28/1 Pes/Vis 20/80 Harman iplik) belirli viskozite ve hız değerleri için 2 tekneli haşıl prosesinden geçmiş ve haş1llı iplikler üretilmiştir. Üretilen ipliklere rutubet tayini (İplik üzerindeki su miktarı), haşıl alma oranı tespiti (haşıllı iplikle haşılsız iplik arasındaki ağırlık farkının \% cinsinden değeri) ve mukavemet testi (kopmaya karşı direnç) uygulanmıştır. Üretilen iplik numunesi dokunmuş ve dokuma makinesi randımanı kaydedilmiştir. Seçilen iplik için aşağıdaki Çizelge 4'de makine ayarları verilmiştir.

Çizelge 5'de viskozite $28 \mathrm{Ns} / \mathrm{m}^{2}$, viskozite 30 $\mathrm{Ns} / \mathrm{m}^{2}$, viskozite $40 \mathrm{Ns} / \mathrm{m}^{2}$ için kullanılan haş1 çözeltileri reçetesi verilmiştir. İplikler, Beninnger marka haş1 makinesinde haşıllanmıştır. İplik mukavemetlerinin ölçümü için TITAN mukavemet test cihazı kullanılmış ve testler EN ISO 2062 standardına göre yapılmıştır. 


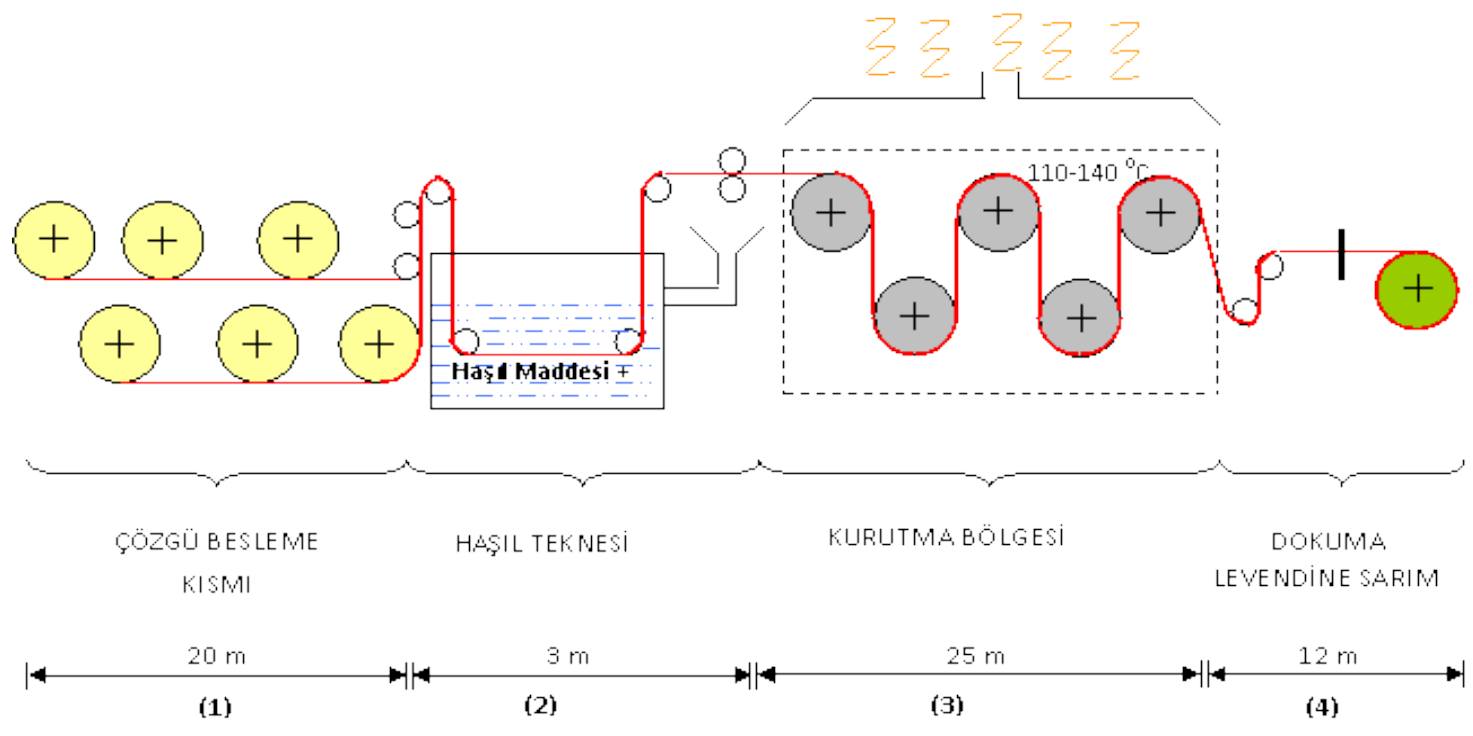

Şekil 3. Haşıl makinesinde iş akışı [5]

Çizelge 3.Haşıllama işlemi iş etüdü (1000 m'lik çözgü ipliği için)

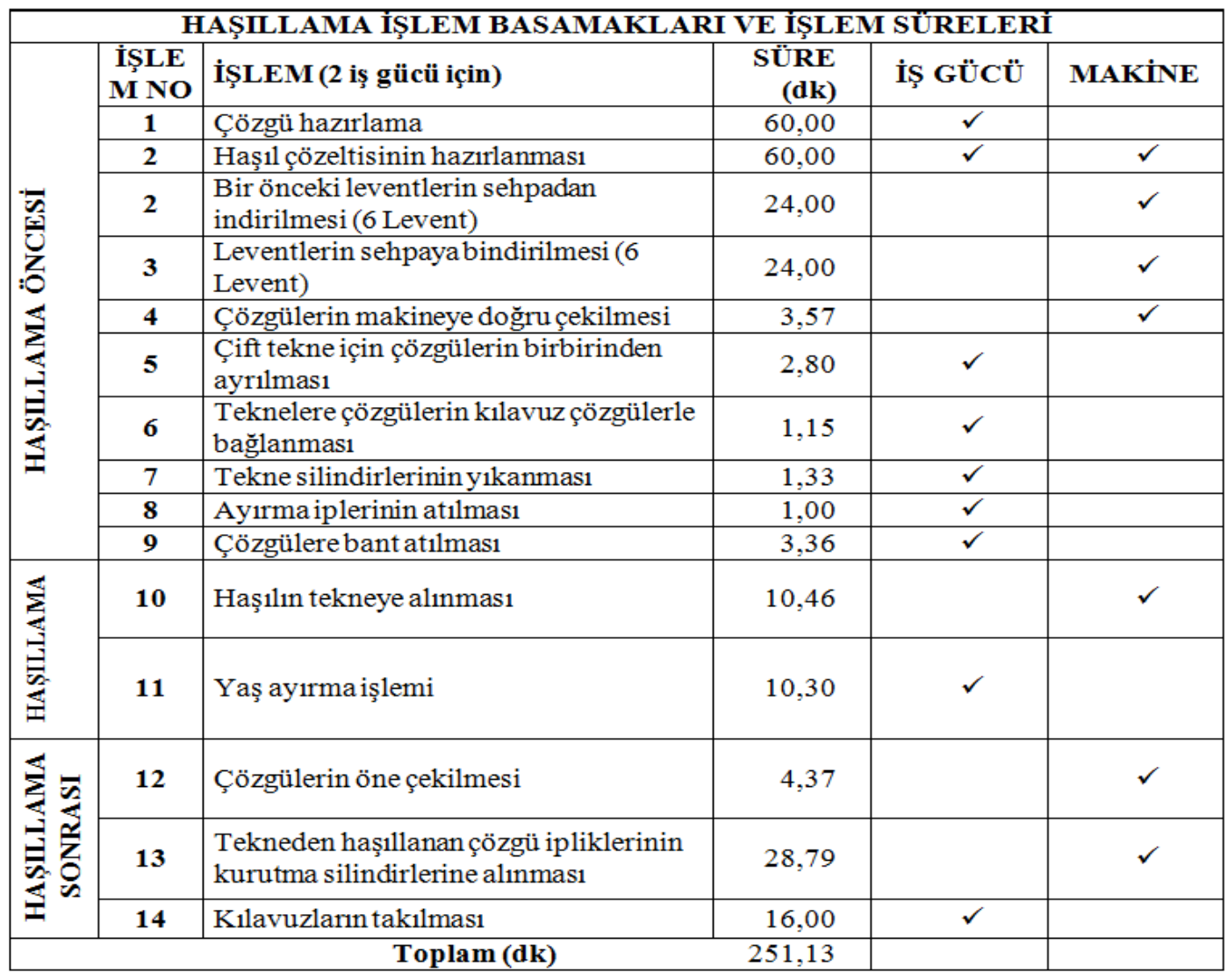




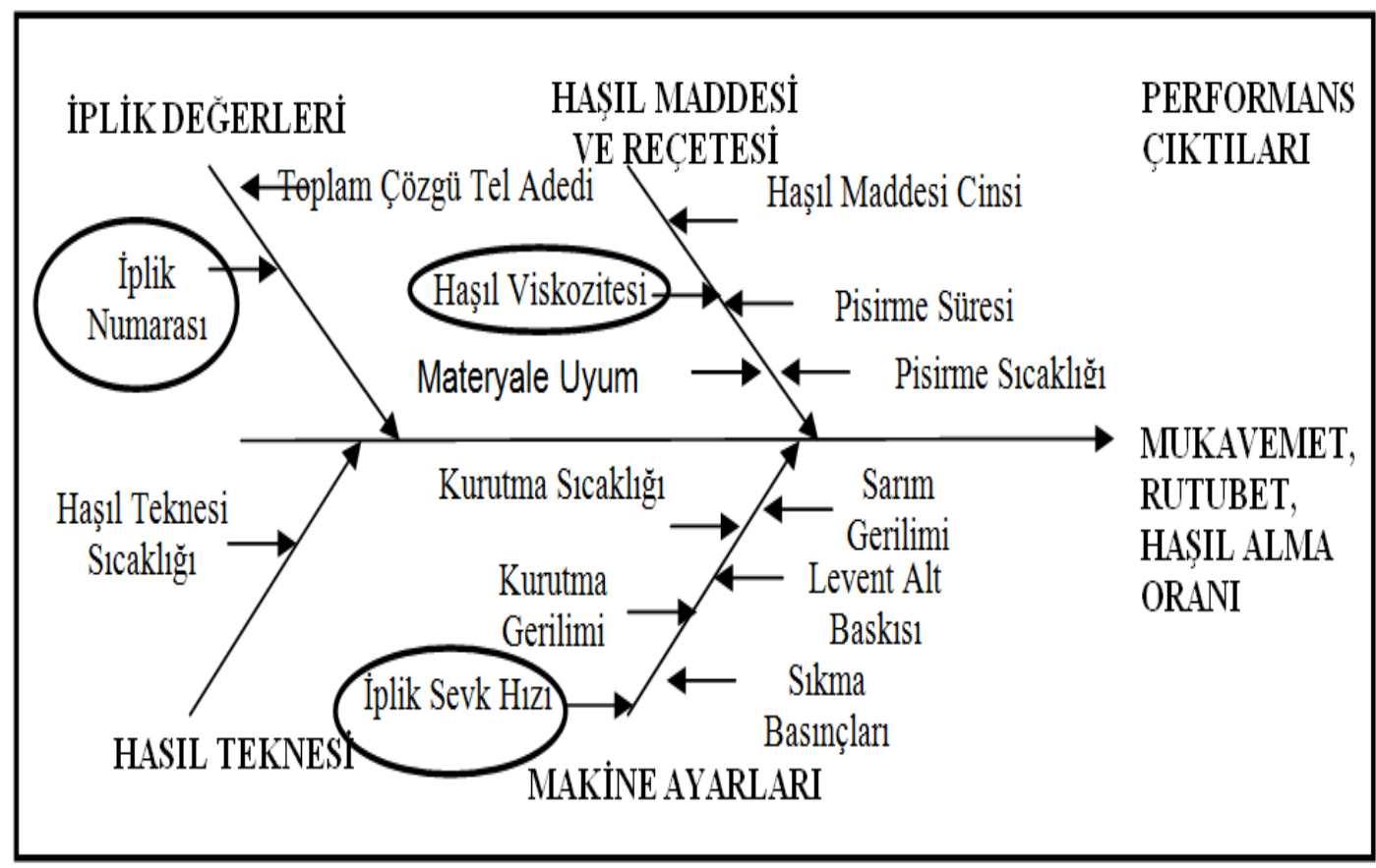

Şekil 4. Mukavemet, rutubet ve haşıl alma çıktısı için neden-sonuç diyagramı

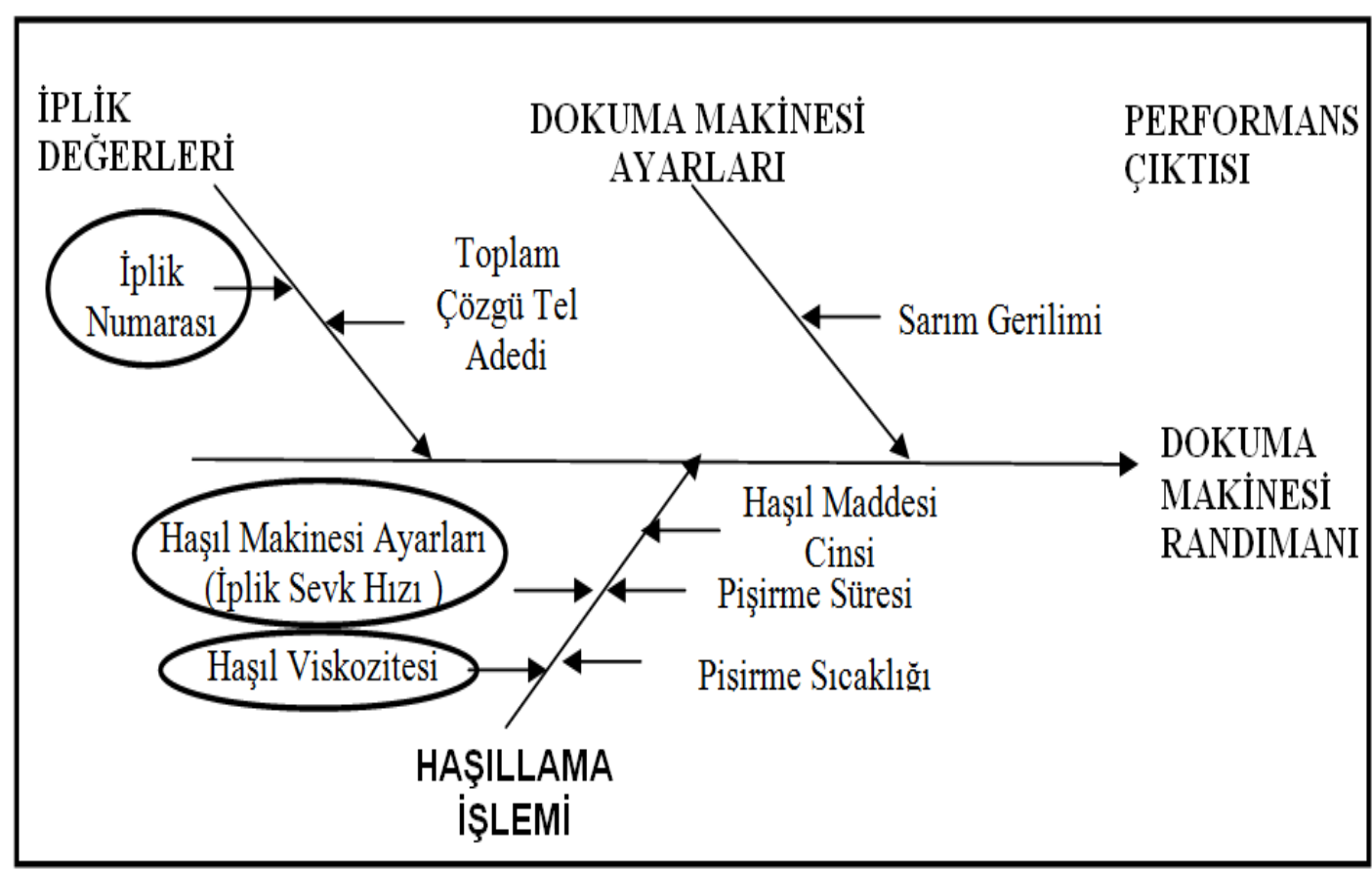

Şekil 5. Dokuma makinesi randımanı çıktısı için neden-sonuç diyagramı 
Çizelge 4. Ne 28/1 pes/vis 20/80 harman makine ayarlar1

\begin{tabular}{|l|l|}
\hline Tekne Sıcaklığ $\left({ }^{0} \mathrm{C}\right)$ & 85 \\
\hline $\begin{array}{l}\text { Kurutma Silindirleri Sıcaklığ } \\
\left({ }^{0} \mathrm{C}\right)\end{array}$ & 135 \\
\hline $\begin{array}{l}\text { Haşıl Teknesi Baskı Silindirleri } \\
(\mathrm{N})\end{array}$ & A Teknesi: 15 \\
\cline { 2 - 2 } $\begin{array}{l}\text { Çözgü Besleme Bölümünde } \\
\text { Levent Gerilimi (N) }\end{array}$ & B Teknesi: 20 \\
\hline & 1500 \\
Tekne Gerilimleri (N) & $\begin{array}{l}\text { A teknesi : } \\
1500\end{array}$ \\
\cline { 2 - 2 } & B teknesi: \\
\hline $\begin{array}{l}\text { Dokuma Levendine Sarım } \\
\text { Siklığ1 (N) }\end{array}$ & 1500 \\
\hline $\begin{array}{l}\text { Çözgünün Haşı Teknesinden } \\
\text { Geçiş Hızı (sevk hızı) (m/dk) }\end{array}$ & 50 \\
\hline
\end{tabular}

Çizelge 5. Ne 28/1 pes/vis 20/80 harman için kullanılan haşıl reçeteleri

\begin{tabular}{|l|c|c|c|}
\hline $\begin{array}{l}\text { Haş1l } \\
\text { Çözeltisi } \\
\text { Maddeleri } \\
\begin{array}{l}\text { (Ticari } \\
\text { isimleriyle) }\end{array}\end{array}$ & $\begin{array}{c}|c| \\
28 \\
\left(\mathrm{Ns} / \mathrm{m}^{2}\right)\end{array}$ & $\begin{array}{c}\text { Miktarı }(\mathrm{kg}) \\
30\left(\mathrm{Ns} / \mathrm{m}^{2}\right)\end{array}$ & \begin{tabular}{c} 
Viskozite \\
\cline { 2 - 4 }$\left(\mathrm{Ns} / \mathrm{m}^{2}\right)$
\end{tabular} \\
\hline SU & 350 & 350 & 350 \\
\hline $\begin{array}{l}\text { EMSIZE } \\
\text { CMS 60 }\end{array}$ & 20 & 25 & 30 \\
\hline $\begin{array}{l}\text { EMSIZE } \\
\text { E14 }\end{array}$ & 10 & 10 & 10 \\
\hline $\begin{array}{l}\text { ELVANO } \\
\text { L T66 }\end{array}$ & 20 & 25 & 30 \\
\hline VAKS & 2 & 2 & 2 \\
\hline
\end{tabular}

\subsection{Bulgular}

Haşı prosesinde yapılan deney sonuçları Şekil 6'da toplu bir şekilde grafik şeklinde görülmektedir. Haşıl alma oranı, bu karışım materyali için işletme koşullarında \%12-13 civarında olmalıdır. Bu durumda Şekil 6a'ya göre en uygun Haşıl alma oranı viskozite $40 \mathrm{Ns} / \mathrm{m}^{2}$ ve hızın da 70 m/dk olduğu değerdir. Rutubet değeri, bu karışım materyali için işletme koşullarında \%6 civarında olmalıdır. Bu durumda Şekil 6b'ye göre en uygun Rutubet değeri viskozite $30 \mathrm{Ns} / \mathrm{m}^{2}$ ve hızın da $50 \mathrm{~m} / \mathrm{dk}$ olduğu değerdir.

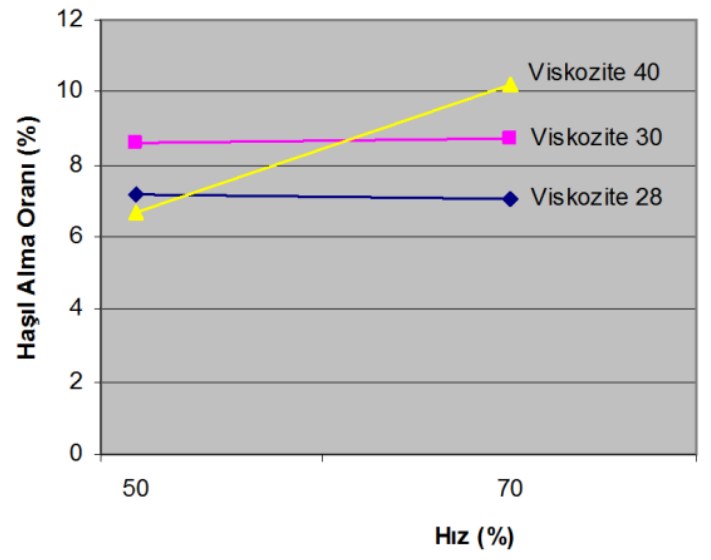

(a) Haşıl Alma

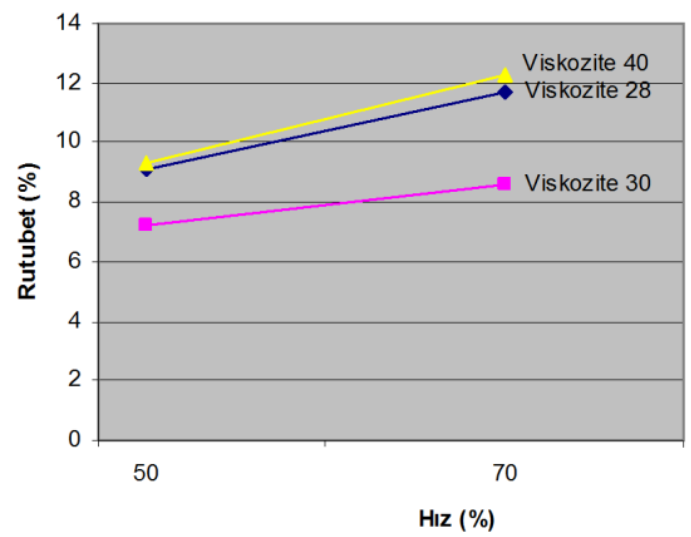

(b) Rutubet

Şekil 6. Ne 28/1 Pes/Vis 20/80 harman materyali için haşıl makinesi hızının performans parametrelerine etkisi

Ne 28/1 Pes/Vis 20/80 Harman materyali için viskozite 28,30 ve $40 \mathrm{Ns} / \mathrm{m}^{2}$ için 50 ve $70 \mathrm{~m} / \mathrm{dk}$ hızlarda elde edilen Haşıl alma(\%), Rutubet (\%), Dokuma makinesi Randımanı (\%) ve mukavemet (cN/Tex) değerleri toplu halde tablo şeklinde Çizelge 6'da özetlenmiştir. 
Çizelge 6. Ne 28/1 pes/vis 20/80 harman materyali için genel değerlendirme

\begin{tabular}{|c|c|c|c|c|c|c|c|}
\hline \multicolumn{2}{|c|}{$\begin{array}{c}\text { Deney Parametreleri } \\
\text { (Girdi Değişkenleri) }\end{array}$} & \multicolumn{6}{|c|}{$\begin{array}{c}\text { Çıktılar } \\
\text { (Yanıt Değişkenleri) }\end{array}$} \\
\hline \multirow{2}{*}{$\begin{array}{c}\text { Hrz } \\
(\mathbf{m} / \mathbf{d k})\end{array}$} & \multirow{2}{*}{$\begin{array}{l}\text { Viskozite } \\
\left(\mathrm{Ns} / \mathbf{m}^{2}\right)\end{array}$} & \multicolumn{3}{|c|}{ Haşıl alma (\%) } & \multirow{2}{*}{$\begin{array}{c}\text { Rutubet } \\
(\%)\end{array}$} & \multirow{2}{*}{$\begin{array}{c}\text { Randıman } \\
(\%)\end{array}$} & \multirow{2}{*}{$\begin{array}{c}\text { Mukavemet } \\
\text { (cN/tex) }\end{array}$} \\
\hline & & $\mathrm{A}$ & B & Ort. & & & \\
\hline 50 & 28 & 7,3 & 7 & 7,15 & 9,1 & 96,6 & 22,72 \\
\hline 70 & 28 & 7 & 7,1 & 7,05 & 11,7 & 93,9 & 22,22 \\
\hline 50 & 30 & 7,9 & 9,3 & 8,6 & 7,2 & 96,9 & 21,41 \\
\hline 70 & 30 & 8,7 & 8,7 & 8,7 & 8,6 & 94,7 & 21,64 \\
\hline 50 & 40 & 7,9 & 5,5 & 6,7 & 9,32 & 96,9 & 22,50 \\
\hline 70 & 40 & 10,1 & 10,3 & 10,2 & 12,3 & 97,7 & 21,27 \\
\hline
\end{tabular}

\section{SONUÇ}

Haşıllama Prosesi, dokuma prosesi öncesi yürütülen ve dokuma işleminin performansını doğrudan etkileyen, işletmede kapladığ (yaklaşık $60 \mathrm{~m}$ ), tükettiği enerji (Buhar elde etmek için harcanan enerji doğal gaz enerjisi olup ayda 150.000 standart $\mathrm{m}^{3}$ 'tür. Haşıl makinesinin çekmiş olduğu elektrik enerjisi ise saatte $32 \mathrm{~kW}$ 'dir), çevreye verdiği atık miktarı (kullanılmış haşıl çözeltisinde mevcut bulunan haşıl maddeleri, atık su) ve proseste uzmanlık gerektiren yönüyle incelenmesi gereken önemli bir prosestir. $\mathrm{Bu}$ proseste $1000 \mathrm{~m}$ çözgü ipliği için yapılan işler iş etüdü ile gözlem sonucu ölçülmüş ve yaklaşık 252 $\mathrm{dk}$ sürdüğ̈̈ tespit edilmiştir. Bu süre de yaklaşık 4,5 saate denk gelmektedir (1000 m'lik çözgü ipliğinin haşıllanması için geçen süre).

$\mathrm{Bu}$ çalışmada, haşıl prosesine göre iplik türleri, işletme haşıl prosesi verileri, haşıl maddeleri ve haşıl prosesi iş etüdü anlatılmış ve haşıl prosesine etki eden parametreler belirlendikten sonra $\mathrm{Ne}$ 28/1 Pes/Vis 20/80 harman iplik seçilerek bu iplikler 28,30 ve $40 \mathrm{Ns} / \mathrm{m}^{2}$ viskozite, 50 ve 70 $\mathrm{m} / \mathrm{dk}$ hızlarda haşıllanarak haşıl alma oranı, iplik rutubeti, çözgü mukavemeti ve dokuma makinesi randımanı ölçülmüştür. Değerlendirmeler sonunda hızın haşıllı ipliğin performans parametreleri üzerinde etkili olduğu görülmüştür. Deneysel çalışmada Ne 28/1 Pes/Vis 20/80 harmandaki ipliğin mukavemet performans çıktısı için de bu karışımda işletme koşullarına göre en uygun haşıllama şartının viskozite $28 \mathrm{Ns} / \mathrm{m}^{2}$ ve hızın da $50 \mathrm{~m} / \mathrm{dk}$ olduğu tespit edilmiştir.

\section{KAYNAKLAR}

1. Hari P. K., Tewary A., 1985. Role of Moisture in the Performance of Sized Yarn, Textile Research Journal, Sayı 9,vol 55 sayfa 567-571,

2. Eken, S. 1992. Haşıl İşleminin Çözgü Kopuşlarına Etkisi, Yüksek Lisans Tezi, Uludağ Üniversitesi, Fen Bilimleri Enstitüsü, Tekstil Mühendisliği Anabilim Dalı, Bursa.

3. Trauter, J.ve Stegmaier, T. 1992. ITV- Haşıl Regülatörü Sıcam ile Haşılda Yeni Kalite Standartları", Tekstil Maraton Dergisi, Temmuz-Ağustos, Sayfa 40-49.

4. Kovacevic, S., Kresimir, H., Grancaric, Z., 2000. Influence Of Warp Loading On Weaving Machines Upon Yarn Deformation", Textile Research Journal, July, page 603-610

5. Sabır, E.C, Sarpkaya, Ç., 2011. Haşıl Prosesinin Önemi, Maliyet Analizi, Karşılaşılan Sorunlar ve Çözüm Önerileri, Tekstil ve Mühendis Dergisi,Yıl 18, Say1: 83,Sayfa 8-13.

6. Djordjevic, S., Nikolic, L., Urosevic, S., Djordjevic, D., 2012. Importance of Polymer 
Size Rheology for Efficient Sizing of Cotton Warp Yarns", Tekstil ve Konfeksiyon Dergisi, 2, Sayfa 77-82.

7. Gemci R., 2000. Dokuma Teknolojisi Ders Notu, Kahramanmaraş Sütçüimam Üniversitesi, Mühendislik - Mimarlık Fakültesi, Tekstil Mühendisliği Bölümü, Kahramanmaraş,

8. www.dogakimya.com/pratikbilgiler.htm, 2009. 